\title{
Functional Defect in Neutrophil Cytosols from Two Patients with Autosomal Recessive Cytochrome-positive Chronic Granulomatous Disease
}

\author{
John T. Curnutte, Patricia J. Scott, and Bernard M. Babior \\ Department of Basic and Clinical Research, Research Institute of Scripps Clinic, La Jolla, California 92037
}

\begin{abstract}
The kinetics of activation of the respiratory burst oxidase in the cell-free oxidase-activating system have been explained by a three-stage mechanism in which the membrane-associated oxidase components $\mathrm{M}$ : (a) take up a cytosolic factor $\mathrm{S}$ to form a complex M'S that is (b) slowly converted in the second stage to a precatalytic species [MS]*, which finally (c) takes up two more (possibly identical) cytosolic components, $C_{\alpha}$ and $C_{\beta}$, to successively generate $[\mathrm{M} S]^{*} \mathrm{C}_{\alpha}$, a low-activity (i.e., high $K_{\mathrm{m}}$ ) oxidase, and finally $[\mathrm{M} S]^{*} \mathrm{C}_{\alpha} \mathrm{C}_{\beta}$, the ordinary (i.e., low $K_{\mathrm{m}}$ ) oxidase (Babior, B. M., R. Kuver, and J. T. Curnutte. 1988. J. Biol. Chem. 263:1713-1718). Studies with the cell-free oxidase-activating system from normal neutrophils and from neutrophils obtained from two patients with type II (autosomal recessive cytochrome-positive) chronic granulomatous disease (CGD) have suggested that $(a)$ the defective element in the cytosol from patient neutrophils is $S ;(b)$ in normal neutrophil cytosol, $S$ is limiting with respect to $M$; and (c) $C_{\alpha}$ and $C_{\beta}$ interact cooperatively with the activated precursor complex [M'S]*. It was further speculated that $S$ might be identical to the nonphosphorylated progenitor of the phosphorylated 48-kD proteins that are missing in certain forms of CGD, and that other forms of type II CGD besides the one described in this report remain to be discovered.
\end{abstract}

\section{Introduction}

The respiratory burst oxidase is the enzyme chiefly responsible for the production of microbicidal oxidants by neutrophils and other professional phagocytes. It is a membrane-bound oxidase, dormant in resting cells, that catalyzes the reduction of oxygen to superoxide $\left(\mathrm{O}_{2}^{-}\right)$at the expense of NADPH (1): $2 \mathrm{O}_{2}$ $+\mathrm{NADPH} \rightarrow 2 \mathrm{O}_{2}^{-}+\mathrm{NADP}^{+}+\mathrm{H}^{+}$. Recent investigations using a cell-free oxidase-activating system have shown it to be a complex species requiring for the expression of its activity a number of components, some from the plasma membrane (2-6) and others from the cytosol $(2,3,7-16)$.

Chronic granulomatous disease (CGD) ${ }^{1}$ is an inherited disorder characterized by the inability of phagocytes from af-

Address correspondence to Dr. John T. Curnutte, Department of Basic and Clinical Research, Scripps Clinic and Research Foundation, BCR-7, 10666 North Torrey Pines Road, La Jolla, CA 92037.

Received for publication 18 July 1988 and in revised form 4 November 1988.

1. Abbreviations used in this paper: CGD, chronic granulomatous disease.

J. Clin. Invest.

(c) The American Society for Clinical Investigation, Inc. $0021-9738 / 89 / 04 / 1236 / 05 \quad \$ 2.00$

Volume 83, April 1989, 1236-1240 fected patients to manufacture microbicidal oxidants because of a defect in the respiratory burst oxidase or its activating apparatus (17). It has been shown over the past few years that CGD can be classified into several distinct types based on mode of inheritance, on whether or not a membrane-associated heme protein known as cytochrome $b_{558}$ is present in the affected phagocytes (18-20), and on whether the functionally abnormal component resides in the cytosol or the membrane of the defective phagocyte $(3,6,8,20,21)$. With regard to those forms of CGD caused by membrane defects, the genes for both the 91- and 22-kD subunits of the cytochrome have now been cloned $(22,23)$, and Dinauer et al. showed that $\mathrm{X}$-linked cytochrome-negative CGD, the most common type, is associated with a lesion involving the gene encoding the larger subunit (24). Defects in cytosol-based components were first demonstrated by Curnutte et al., who showed that cytosols from seven patients with autosomal recessive cytochrome-positive type of CGD (type II CGD (Scripps classifcation [20])) failed to support $\mathrm{O}_{2}^{-}$production in the cell-free oxidase-activating system (21). We now present evidence that the biochemical defect in two patients with type II CGD involves a cytosolic protein that participates at an early stage in the activation of the oxidase.

\section{Methods}

Cells from both normal subjects and CGD patients were obtained by leukapheresis after obtaining informed consent. Dexamethasone (4-mg doses 12 and $2 \mathrm{~h}$ before the start of pheresis) was given to normal donors to augment neutrophil yields; this treatment did not alter the properties of subcellular fractions prepared from the cells. Purification of neutrophils was subsequently carried out as described before (25), except that dextran sedimentation was omitted. Neutrophil yields were $0.6-2.2 \times 10^{10}$ cells/donor. Cells were disrupted by nitrogen cavitation and cytosol and solubilized membranes were prepared from the neutrophil cavitates according to a published method $(2,3)$, solubilizing the membranes in $\mathrm{Na}$ deoxycholate at a final detergent concentration of $1.6 \%(\mathrm{wt} / \mathrm{vol})$ in buffer containing $25 \%(\mathrm{vol} / \mathrm{vol})$ glycerol and other constituents as previously described (6). Protein concentrations of these fractions were previously determined to be as follows (2): cytosol, $250 \pm 16 \mathrm{SE} \mu \mathrm{g} / 10^{7}$ cell eq; solubilized membranes, $25.7 \pm 1.4 \mathrm{SE} \mu \mathrm{g} / 10^{7}$ cell eq. The cytosol preparations always contained $9 \times 10^{7}$ cell eq $/ \mathrm{ml}$.

$\mathrm{O}_{2}^{-}$production was assayed as described elsewhere (2), except that the membranes were incubated for $3.5 \mathrm{~min}$ with cytosol or buffer, SDS, and $\mathrm{Mg}^{2+}$ in the absence of NADPH to preactivate the oxidase before the addition of the reducing agent, and the cytochrome $c$ concentration in the assay mixture was $0.15 \mathrm{mM}$. Preliminary experiments showed that in the presence of normal cytosol the oxidase was nearly fully activated during the 3.5 -min preincubation and that its activity did not decline over the next $1.5 \mathrm{~min}$. The maximum rate of $\mathrm{O}_{2}^{-}$production ( $V_{\infty}$, previously referred to as $V$ [2]) was always observed within $10 \mathrm{~s}$ after adding NADPH, and was sustained for at least $30 \mathrm{~s}$. For these studies, $V_{\infty}$ was evaluated by eye rather than by computer, because we had found in an earlier study that ocular estimates of $V_{\infty}$ were in good agreement with computer-generated values (2). 


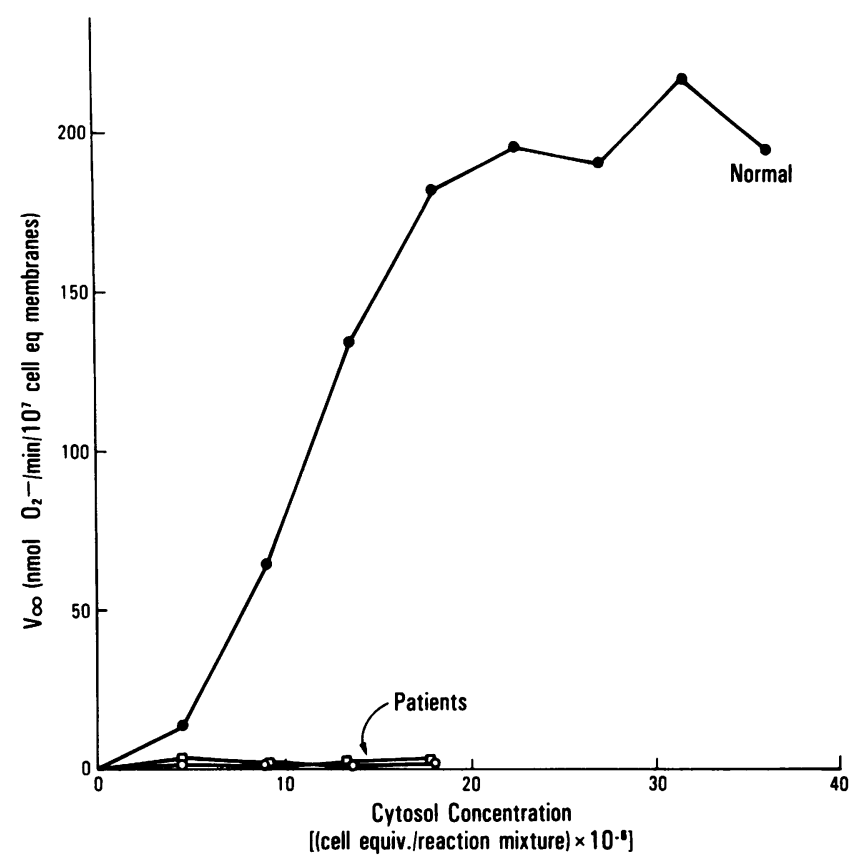

Figure 1. $V_{\infty}$ as a function of the concentration of normal and type II CGD cytosol. Incubations were carried out as described in Methods using membranes at $3.1 \times 10^{6}$ cell eq/reaction mixture $(0.75 \mathrm{ml}$ total vol) and various concentrations of normal and CGD cytosol as shown. Reactions were started with NADPH. The normal curve (๑) is representative of results obtained in seven separate experiments, each using cytosol from a different donor. The CGD patient curves (O, patient J.C.; $\square$, patient J.G.) confirm the results of multiple determinations using CGD cytosol at $10^{7}$ cell eq/reaction.

\section{Results}

Failure of the CGD cytosols to activate the respiratory burst oxidase in the cell-free system. In autosomal recessive cytochrome-positive (type II) CGD, neutrophil cytosols have been reported to be unable to fulfill the role of normal cytosol in the cell-free oxidase-activating system (21). This defect was confirmed in cytosols from patients J.G. and J.C., both of whom have type II CGD (Fig. 1). The mixtures containing the CGD cytosols yielded little oxidase activity at any of the concentrations tested. In contrast, oxidase activity as a function of normal cytosol concentration showed the usual sigmoidal curve (2), with greater-than-first-order kinetics at low levels of cytosol and a long plateau that appears as the cytosol concentration begins to exceed the concentration of neutrophil membranes (both expressed in terms of cell equivalents).

The lag. The components of the cell-free oxidase-activating system include detergent, $\mathrm{Mg}^{2+}$, and cytosol and plasma membrane from resting neutrophils. When the oxidase in this system is activated in the presence of substrate (i.e., NADPH), the early course of the $\mathrm{O}_{2}^{-}$-forming reaction is characterized by a lag that reflects the time required to convert the dormant oxidase to its active form $(2,6)$. We have previously shown that this lag can be abolished by incubating the components together for several minutes before adding NADPH to the assay mixture $(2,3)$. To ascertain whether type II CGD cytosol could likewise abolish the lag, the following experiment was conducted. Reaction mixtures containing plasma membranes, detergent, $\mathrm{Mg}^{2+}$, and a quantity of test cytosol (normal or type
II CGD cytosol, or buffer) were preincubated for $3.5 \mathrm{~min}$ to activate the respiratory burst oxidase in the absence of substrate. $\mathrm{O}_{2}^{-}$production was then initiated by the addition of normal cytosol plus NADPH. (The normal cytosol was needed in the initiating mixture to supply the component missing from the CGD cytosol, which by itself showed only a very limited capacity [ $<2 \%$ of normal] to support respiratory burst oxidase activity in the cell-free activating system.) The results (Fig. 2) showed that the lag was largely eliminated by preincubation with normal cytosol (curve $a$ in each panel) but was unaltered by a preincubation in which normal cytosol was replaced by type II CGD cytosol (curve $b$, panels $B$ and $C$ ). These conclusions were confirmed by the finding that in reaction mixtures in which the preincubation was carried out with normal cytosol, the rate of $\mathrm{O}_{2}^{-}$production very early in the course of the reaction (estimated as the amount of $\mathrm{O}_{2}^{-}$produced during the first $30 \mathrm{~s}$ of the reaction) was much closer to the maximum rate (estimated as the amount produced during $30 \mathrm{~s}$ at maximum velocity) than in mixtures in which the preincubation was carried out with either CGD cytosol or buffer (Table I). The lag was not due to the presence of a competing $\mathrm{O}_{2}^{-}$-consuming system in the CGD cytosol that lost activity (or was depleted) in the first 2-3 min of the reaction, because when the experiments were carried out without preincubation, the time course of $\mathrm{O}_{2}^{-}$production by mixtures of

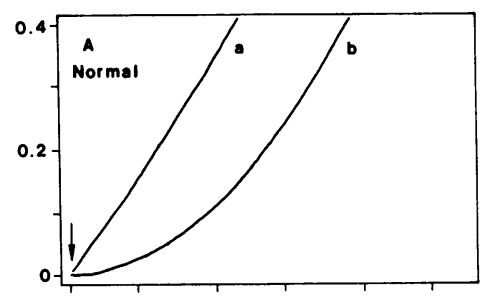

Figure 2. Effect of type II CGD cytosol on the time course of activation of the respiratory burst oxidase (the lag). Preincubations were conducted as outlined in Methods. Preincubation mixtures contained

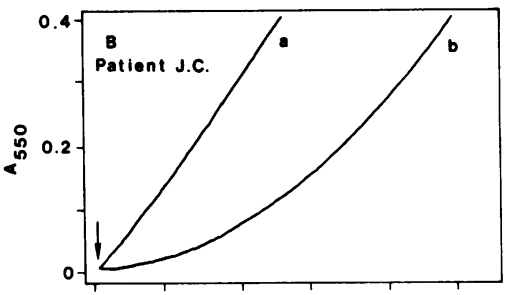
an initial portion (0.11 $\mathrm{ml}$ ) of cytosol equivalent (normal cytosol, CGD cytosol, or buffer). At $t=0, \mathrm{O}_{2}^{-}$ production was started by adding NADPH (arrows) together with a portion $(0.11 \mathrm{ml})$ of a

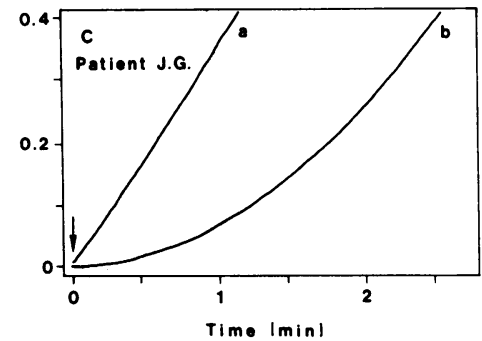
different cytosol equivalent (normal cytosol, CGD cytosol, or buffer; final reaction vol 0.75 $\mathrm{ml}$ ). $\mathrm{O}_{2}^{-}$production was then followed spectrophotometrically at 550 $\mathrm{nm}$ as described in Methods. In each experiment, one of the por-

tions of cytosol equivalent consisted of normal cytosol, while the other consisted of buffer $(A)$, cytosol from patient J.C. $(B)$, or cytosol from patient J.G. $(C)$. Curve $a$ shows the course of $\mathrm{O}_{2}^{-}$production when normal cytosol was added first, while curve $b$ shows the course of $\mathrm{O}_{2}^{-}$production when the CGD cytosol or buffer was added first. In every case, curve $a$ showed little or no lag, while curve $b$ displayed a full lag. These results are representative of six experiments, four using cytosol from patient J.G. and three from patient J.C. The data presented above were obtained on the same day using a single preparation of normal cytosol. 
Table I. Early Rate of $\mathrm{O}_{2}^{-}$Production as a Fraction of the Maximum Rate of $\mathrm{O}_{2}^{-}$Production in Reaction Mixtures in which Normal Cytosol, CGD Cytosol, or Buffer Were Preincubated under Oxidase-activating Conditions

\begin{tabular}{lc}
\hline \multicolumn{1}{c}{ Preincubation } & Early rate/maximum rate \\
\hline Normal cytosol & $0.99 \pm 0.01(5)$ \\
J.C. cytosol & $0.19 \pm 0.06(3)$ \\
J.G. cytosol & $0.16 \pm 0.02(4)$ \\
Buffer & $0.20 \pm 0.03(6)$ \\
\hline
\end{tabular}

Experiments were conducted as described in Fig. 2. The early rate/ maximum rate ratio was taken to be the amount of $\mathrm{O}_{2}^{-}$produced during the first $30 \mathrm{~s}$ of the reaction divided by the amount produced during $30 \mathrm{~s}$ at maximum velocity. Results are expressed as the mean $\pm 1 \mathrm{SE}$ for the number of experiments shown in parentheses.

normal and CGD cytosol was virtually identical to that seen with mixtures in which the CGD cytosol was replaced by buffer.

High $K_{m}$ vs. low $K_{m}$ oxidase. In our earlier kinetic study (2) of the cell-free activating system, we obtained evidence for the existence of two forms of the respiratory burst oxidase: a lowactivity species with a relatively high $K_{\mathrm{m}}$ for NADPH $(\approx 150$ $\mu \mathrm{M})$ that was formed at low cytosol concentrations, and another much more active species with a low $K_{\mathrm{m}}$ for NADPH $\left(\approx 40 \mu \mathrm{M}\right.$, similar to $K_{\mathrm{m}}$ values obtained in numerous earlier studies of the respiratory burst oxidase $[1,6,17])$ that was generated at high cytosol concentrations. We have now confirmed this result at three cytosol concentrations (Table II), showing a statistically significant difference in the $K_{\mathrm{m}}$ for NADPH between the oxidase generated at the lowest concentration of cytosol and the oxidase formed at each of the two higher cytosol concentrations ( $P<0.002$ for each difference). To determine whether type II CGD cytosol, though unable to activate the oxidase, was capable of supporting the formation of the ordinary (i.e., low $K_{\mathrm{m}}$ ) as opposed to the low-activity (i.e., high $K_{\mathrm{m}}$ ) enzyme, an experiment was performed in which the $K_{\mathrm{m}}$ of oxidase generated at a low cytosol concentration was compared with the $K_{\mathrm{m}}$ observed when the low-cytosol activating system was supplemented with additional cytosol, either normal or type II CGD. The results (Table III) showed that as long as enough normal cytosol was present to activate the oxidase, supplementation with cytosol from either patient with type II CGD permitted the generation of the ordinary form of the enzyme, even when the amount of normal cytosol in the

Table II. Effect of Cytosol Concentration on the $K_{m}$ and $V_{\max }$ for $N A D P H$

\begin{tabular}{ccc}
\hline Cytosol concentration & $K_{\mathrm{m}}$ & $V_{\max }$ \\
\hline $10^{-6} \times$ cell eq/assay & $\mu M$ & $\begin{array}{c}\text { umol } O_{2}^{-} / \text {min per mg } \\
\text { membrane protein }\end{array}$ \\
$18(6)$ & $38.9 \pm 5.2 \mathrm{SE}$ & $12.1 \pm 1.1$ \\
$10(4)$ & $39.1 \pm 4.7 \mathrm{SE}$ & $6.2 \pm 1.6$ \\
$4(14)$ & $136 \pm 13.4 \mathrm{SE}$ & $1.7 \pm 0.2$ \\
\hline
\end{tabular}

Incubations (total vol $0.75 \mathrm{ml}$ ) were conducted as described in Methods. To calculate kinetic parameters, $V_{\infty}$ was fitted to a Lineweaver-Burk plot using a least-squares program. If $r$ for this fit was $<0.9$, the experiment was discarded. Figures in parentheses indicate the number of experiments used for calculating $K_{\mathrm{m}}$ and $V_{\max }$.
Table III. Effect of Type II CGD Cytosol on the $K_{m}$ of the Lowaffinity Form of the Respiratory Burst Oxidase

\begin{tabular}{|c|c|c|c|}
\hline \multicolumn{2}{|c|}{ Cytosol } & \multirow[b]{2}{*}{$K_{\mathrm{m}}$} & \multirow[b]{2}{*}{$V_{\max }$} \\
\hline Normal & CGD & & \\
\hline & & $\mu M$ & $\begin{array}{c}\text { umol } O_{2} / \text { min per mg } \\
\text { membrane protein }\end{array}$ \\
\hline Low & None & 115.1 & 0.9 \\
\hline Low & CGD (J.C.) & 35.1 & 3.1 \\
\hline Low & CGD (J.G.) & 25.0 & 2.6 \\
\hline High & None & 27.7 & 9.8 \\
\hline
\end{tabular}

The low- and high-affinity forms of the respiratory burst oxidase were generated as described in Table II using either a low $\left(4 \times 10^{6}\right.$ cell eq/reaction) or high $\left(16.6 \times 10^{6}\right.$ cell eq/reaction) concentration of normal cytosol, respectively. Where indicated, cytosol from one of the two type II CGD patients (J.C. and J.G.) was included in the activation mixture at $12.6 \times 10^{6} \mathrm{cell} \mathrm{eq} / \mathrm{reaction}$. The kinetic parameters were calculated as described in Table II. The results of a single experiment using cytosols from both CGD patients are shown. Similar results were obtained in a second experiment using cytosol from patient J.G. only. In reaction mixtures containing patient cytosols only, $\mathrm{O}_{2}^{-}$was produced at $<1 \%$ of the rate seen with normal cytosols incubated under identical conditions.

activation mixture was so small that without such supplementation only the low-activity oxidase was produced.

The order of the oxidase-activating reaction. During the lag phase of the reaction catalyzed by the cell-free activation system, the rate of production of $\mathrm{O}_{2}^{-}$makes an asymptotic approach to a constant final velocity ( $V_{\infty}$, as defined in Methods) that represents the rate of $\mathrm{O}_{2}^{-}$production when all the dormant oxidase has been converted to its catalytically active form. $V_{\infty}$ is thus directly proportional to the concentration of catalytically competent oxidase at full activation. In the earlier kinetic study, $V_{\infty}$ (i.e., the concentration of active oxidase) was estimated to vary with the square of the cytosol concentration, although the true value of the slope of the line from which this estimate was made (a plot of $\log V_{\infty}$ vs. $\log$ cytosol concentration) was actually 2.3. We now have measured $V_{\infty}$ as a function of cytosol concentration with preparations from seven additional normal subjects, and have found the slopes of the $\log$-log plots derived from these results to be $2.52 \pm 0.09 \mathrm{SE}$ (see representative plots [normal] in Fig. 3, $A$ and $B$ ). Similar slopes were obtained using cytosols from each of the three types of CGD in which the defect resides, not in the cytosol, but in the neutrophil membrane (types I, III, and IV; data not shown) $(3,6,8,20)$. We therefore conclude that with respect to the cytosol, the order of the reaction that determines the concentration of oxidase after activation is complete is not 2 , as previously reported, but $\approx 2.5$.

If we are correct in our supposition that multiple components in the cytosol are required for oxidase activity, and if only one of these components is defective in type II CGD while the others are normal, then it would be expected that the reaction order as measured with normal cytosol would be decreased if the measurements were carried out in the presence of excess type II CGD cytosol, because of the normal components that would be contributed to the assay mixtures by the defective cytosol. When this experiment was conducted, it was found that the slope of the $\log -\log$ plot fell to $0.99 \pm 0.04 \mathrm{SE}$ ( $n$ $=3$; Fig. 3). This result provides additional evidence for the occurrence in the cytosol of multiple components necessary 


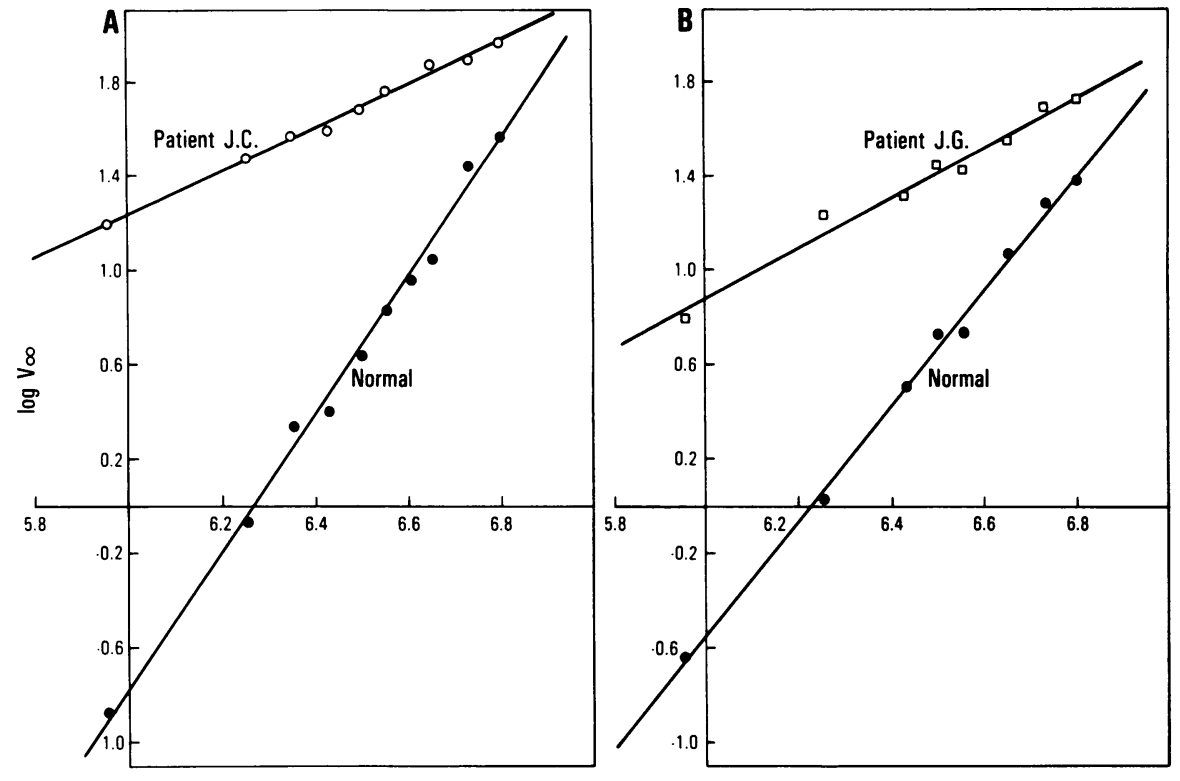

$\log$ (Normal cytosol concentration)
Figure 3. Effect of type II CGD cytosol on the order of the oxidase-activating reaction with respect to normal cytosol. Incubations were carried out as described in Methods, using various concentrations of normal cytosol in the absence $(\bullet)$ or presence $(0, \square)$ of excess CGD cytosol $\left(1.3 \times 10^{7}\right.$ cell eq of CGD cytosol in a total reaction vol of 0.75 $\mathrm{ml}$ ). The figures show log-log plots of $V_{\infty}$ vs. the concentration of normal cytosol. Slopes in the absence and presence of CGD cytosol, respectively, were as follows ( \pm SE of the slope): $(A) 2.90 \pm 0.09$ and $0.92 \pm 0.03 ;(B) 2.45 \pm 0.07$ and $1.07 \pm 0.06$ (obtained by linear least squares regression analysis). The results in B are representative of two separate experiments performed with cytosol from patient J.G. for oxidase activity, and is consistent with the idea that the component missing from type II CGD cytosol normally contributes one order to the reaction that determines the concentration of oxidase in the fully activated system-i.e., that in the normal cell-free activation system, the concentration of oxidase after full activation is directly proportional to the concentration of the component missing from the cytosol of the type II CGD patients' neutrophils.

Complementation. From the foregoing observations, it can be inferred that in the cytosols from J.G. and J.C. the same component is defective. This inference was further tested by complementation studies in which the oxidase-activating capacity of mixtures of the two defective cytosols was examined. In an assay mixture containing equal volumes of the two cytosols, each in a quantity that in the case of normal cytosol would yield a final oxidase activity of $\approx 70 \mathrm{nmol} \mathrm{O}-1 \mathrm{~min}$ per $10^{7}$ cell eq of membranes, the observed oxidase activity was only $2.4 \mathrm{nmol} \mathrm{O}-/ \mathrm{min}$ per $10^{7}$ cell eq. Failure of complementation represents further evidence for the identity of the defect in the two cytosols.

\section{Discussion}

The kinetics of activation of the respiratory burst oxidase in the cell-free system (2) can be explained by the following scheme:

$$
\begin{aligned}
\mathrm{M}+\mathrm{S} \stackrel{\mathrm{Mg}^{2+}}{\rightleftharpoons} \mathrm{M}^{\cdot} \mathrm{S} \stackrel{\mathrm{SDS}, \mathrm{Mg}^{2+}}{\rightarrow}\left[\mathrm{M}^{*} \mathrm{~S}\right]^{*}+\mathrm{C}_{\alpha} \rightleftharpoons\left[\mathrm{M}^{*} \mathrm{~S}\right]^{*} \mathrm{C}_{\alpha} \\
+\mathrm{C}_{\beta} \rightleftharpoons\left[\mathrm{M}^{*} \mathrm{~S}\right]^{*} \mathrm{C}_{\alpha} \mathrm{C}_{\beta},
\end{aligned}
$$

where $M$ represents the membrane-associated components of the resting oxidase; $\mathrm{S}$ is a cytosolic component that forms an activatable precursor complex with the membrane-associated portion of the oxidase; $\mathrm{M}^{*} \mathrm{~S}$ and $\left[\mathrm{M}^{*} \mathrm{~S}\right]^{*}$ are the unactivated and activated forms of that complex, respectively; $\mathrm{C}_{\alpha}$ and $\mathrm{C}_{\beta}$ are the (possibly identical) cytosolic peptides that confer catalytic activity on the activated precursor complex [M*S ${ }^{*}$; and $\left[\mathrm{M}^{*} \mathrm{~S}\right]^{*} \mathrm{C}_{\alpha}$ and $\left[\mathrm{M}^{*} \mathrm{~S}\right]^{*} \mathrm{C}_{\alpha} \mathrm{C}_{\beta}$ are respectively the low-activity (i.e., high $K_{\mathrm{m}}$ ) and ordinary (i.e., low $K_{\mathrm{m}}$ ) forms of the active oxidase. In this scheme, the rate-limiting step in the activation of the oxidase in the cell-free system is the slow, detergent-me- diated conversion of $\mathrm{M}^{*} \mathrm{~S}$ to $\left[\mathrm{M}^{*} \mathrm{~S}\right]^{*}$; the lag is a reflection of this step. In addition, the data from the earlier study require that the equilibrium constant for the reaction preceding the ratelimiting step (i.e., the formation of the activatable precursor complex, M'S) lie far to the right.

The results obtained with the type II CGD cytosol suggest that in neutrophils from some patients with this form of the disease, the defective species is $\mathrm{S}$, the cytosolic component of the activatable precursor complex. The principal evidence supporting this conclusion is the observation that preincubation with cytosol from the type II CGD neutrophils had no effect on the lag, a finding that implicates $S$ as the defective species since $S$ is the only cytosolic factor involved in the rate-limiting step of the oxidase activation reaction. In accord with this interpretation is the ability of the type II CGD cytosol to support the formation of the low $K_{\mathrm{m}}$ oxidase, an observation consistent with the notion that in these patients the cytosolic components necessary for the reactions after the rate-limiting step function in a normal way.

Further conclusions can be drawn from the measurements of the reaction order for normal cytosol in the presence of excess type II CGD cytosol. These measurements indicate that $S$ contributes a value of 1 to the overall order of reaction for cytosol of 2.5 (2). This value of 1 , plus evidence implying that under the present experimental conditions the equilibrium for the reaction $\mathrm{M}+\mathrm{S} \rightleftharpoons \mathrm{M}^{\mathrm{S}} \mathrm{S}$ lies well to the right, suggests that $\mathrm{S}$ is limiting with respect to $M$, and that most of the $S$ in the cytosol is consumed to form M'S shortly after the cytosol is mixed with $\mathrm{Mg}^{2+}$ and the resting membranes. The order of the reaction that remains after the contribution of $S$ is subtracted from the total is 1.5 in cytosol, a nonintegral value. This finding suggests that the association of $\mathrm{C}_{\alpha}$ and $\mathrm{C}_{\beta}$ with the activated precursor complex [M'S]* is a kinetically cooperative interaction, and is also consistent with the abrupt character of the transition between the high $K_{\mathrm{m}}$ and low $K_{\mathrm{m}}$ oxidase as the concentration of normal cytosol is increased in the cell-free activating system.

Taken together with other observations, the findings reported here suggest two further ideas. The first, somewhat speculative, is that the phosphate-free progenitor of the $48-\mathrm{kD}$ 
phosphoproteins that are missing in type II CGD $(26,27)$ may be identical with $\mathrm{S}$, which according to the present results is also missing in this type of CGD. Alternatively, this progenitor may form part of a protein complex that when phosphorylated releases $S$ to interact with $M$. The second is that there exist other varieties of type II CGD besides the type reported here, and that with neutrophil cytosols from at least some of these other types, the lag in $\mathrm{O}_{2}^{-}$production characteristic of the cellfree activating system will be eliminated by preincubation in the absence of NADPH. This latter idea has recently been borne out with the discovery of a patient with type II CGD whose neutrophils show a cytosol defect that is corrected by the CGD cytosols studied in this investigation (28).

\section{Acknowledgments}

This work was supported in part by U. S. Public Health Services grants AI-24227, AI-24838, and RR-00833. Dr. Curnutte is an Established Investigator of the American Heart Association.

The authors dedicate this report to the memory of a friend and colleague, Theodore S. Zimmerman, M.D., who passed away 19 December, 1988.

\section{References}

1. Babior, B. M. 1988. The respiratory burst oxidase. In Hematology/Oncology Clinics of North America. J. T. Curnutte, editor. W. B. Saunders Company, Philadelphia. 201-212.

2. Babior, B. M., R. Kuver, and J. T. Curnutte. 1988. Kinetics of activation of the respiratory burst oxidase in a fully soluble system from human neutrophils. J. Biol. Chem. 263:1713-1718.

3. Curnutte, J. T., R. Kuver, and P. J. Scott. 1987. Activation of neutrophil NADPH oxidase in a cell-free system: partial purification of components and characterization of the activation process. J. Biol. Chem. 262:5563-5569.

4. Pick, E., Y. Bromberg, S. Shpungin, and R. Gadba. 1987. Activation of the superoxide forming NADPH oxidase in a cell-free system by sodium dodecyl sulfate: characterization of the membrane-associated component. J. Biol. Chem. 262:16476-16483.

5. Bellavite, P., F. Corso, S. Dusin, M. Grzeskowiak, V. DellaBianca, and F. Rossi. 1988. Activation of NADPH-dependent superoxide production in plasma membrane extracts of pig neutrophils by phosphatidic acid. J. Biol. Chem. 263:8210-8214.

6. Curnutte, J. T., R. Kuver, and B. M. Babior. 1987. Activation of the respiratory burst oxidase in a fully soluble system from human neutrophils. J. Biol. Chem. 262:6450-6452.

7. Bromberg, Y., and E. Pick. 1984. Unsaturated fatty acids stimulate NADPH-dependent superoxide production by cell-free system derived from macrophages. Cell. Immunol. 88:213-221.

8. Curnutte, J. T. 1985. Activation of human neutrophil nicotinamide adenine dinucleotide phosphate, reduced (triphosphopyridien nucleotide, reduced) oxidase by arachidonic acid in a cell-free system. J. Clin. Invest. 75:1740-1743.

9. McPhail, L. C., P. S. Shirley, C. C. Clayton, and R. Snyderman. 1985. Activation of the respiratory burst enzyme from human neutrophils in a cell-free system. Evidence for a soluble cofactor. J. Clin. Invest. 75:1735-1739.

10. Heyneman, R. A., and R. E. Vercauteren. 1984. Activation of a NADPH oxidase from horse polymorphonuclear leukocytes in a cellfree system. J. Leukocyte Biol. 36:751-759.

11. Bromberg, Y., and E. Pick. 1985. Activation of NADPH-dependent superoxide production in a cell-free system by sodium dodecyl sulfate. J. Biol. Chem. 260:13539-13545.

12. Clark, R. A., K. G. Leidal, D. W. Pearson, and W. M. Nauseef. 1987. NADPH oxidase of human neutrophils: subcellular localization and characterization of an arachidonate-activatable superoxide-generating system. J. Biol. Chem. 262:4065-4074.
13. Gabig, T. G., D. English, L. P. Akard, and M. J. Schell. 1987. Regulation of neutrophil NADPH oxidase activation in a cell-free system by guanine nucleotides and fluoride: evidence for participation of a pertussis and cholera toxin-insensitive $\mathrm{G}$ protein. J. Biol. Chem. 262:1685-1690.

14. Seifert, R., and G. Schultz. 1987. Fatty-acid-induced activation of NADPH oxidase in plasma membranes of human neutrophils depends on neutrophil cytosol and is potentiated by stable guanine nucleotides. Eur. J. Biochem. 162:563-569.

15. Ligeti, E., J. Doussiere, and P. V. Vignais. 1987. Activation of the $\mathrm{O}_{2}^{-}$-generating oxidase in plasma membrane from bovine polymorphonuclear neutrophils by arachidonic acid, a cytosolic factor of protein nature, and nonhydrolyzable analogues of GTP. Biochemistry. 27:193-200.

16. Fujita, I., K. Takeshige, and S. Minakami. 1987. Characterization of the NADPH-dependent superoxide production activation by sodium dodecyl sulfate in a cell-free system of pig neutrophils. Biochim. Biophys. Acta. 931:41-48.

17. Curnutte, J. T., and B. M. Babior. 1987. Chronic granulomatous disease. In Advances in Human Genetics, Vol. 16. H. Harris and K. Hirschhorn, editors. Plenum Publishing Corp., New York. 229-297.

18. Segal, A. W., A. R. Cross, R. C. Garcia, N. Borregaard, N. Valerius, J. F. Soothill, and O. T. G. Jones. 1983. Absence of cytochrome $b$-245 in chronic granulomatous disease: a multicenter European evaluation of its incidence and relevance. N. Engl. J. Med. 308:245-251.

19. Weening, R. S., L. Corbeel, M. de Boer, R. Lutter, R. van Zwieten, M. N. Hamers, and D. Roos. 1985. Cytochrome $b$ deficiency in an autosomal form of chronic granulomatous disease. A third form of chronic granulomatous disease recognized by monocyte hybridization. J. Clin. Invest. 75:915-920.

20. Curnutte, J. T. 1988. Classification of chronic granulomatous disease. In Hematology/Oncology Clinics of North America. J. T. Curnutte, editor. W. B. Saunders Company, Philadelphia. 241-252.

21. Curnutte, J. T., R. L. Berkow, R. L. Roberts, S. B. Shurin, and P. J. Scott. 1988. Chronic granulomatous disease due to a defect in the cytosolic factor required for nicotinamide adenine dinucleotide phosphate oxidase activation. J. Clin. Invest. 81:606-610.

22. Royer-Pokor, B., L. M. Kunkel, A. P. Monaco, S. C. Goff, P. E. Newburger, R. L. Baehner, F. S. Cole, J. T. Curnutte, and S. H. Orkin. 1986. Cloning the gene for an inherited human disorder-chronic granulomatous disease-on the basis of its chromosomal location. Nature (Lond.). 322:32-38.

23. Parkos, C. A., M. C. Dinauer, L. E. Walker, R. A. Allen, A. J. Jesaitis, and S. H. Orkin. 1988. Primary structure and unique expression of the 22-kilodalton light chain of human neutrophil cytochrome b. Proc. Natl. Acad. Sci. USA. 85:3319-3323.

24. Dinauer, M. C., S. H. Orkin, R. Brown, A. J. Jesaitis, and C. A. Parkos. 1987. The glycoprotein encoded by the X-linked chronic granulomatous disease locus is a component of the neutrophil cytochrome $b$ complex. Nature (Lond.). 327:717-720.

25. Badwey, J. A., J. T. Curnutte, C. B. Berde, and M. L. Karnovsky. 1982. Cytochalasin E diminishes the lag phase in the release of superoxide by human neutrophils. Biochem. Biophys. Res. Commun. 106:170-174.

26. Okamura, N., J. T. Curnutte, R. L. Roberts, and B. M. Babior. 1988. Relationship of protein phosphorylation to the activation of the respiratory burst in human neutrophils: defects in the phosphorylation of a group of closely related $48-\mathrm{kDa}$ proteins in two forms of chronic granulomatous disease. J. Biol. Chem. 263:6777-6782.

27. Segal, A. W., P. G. Heyworth, S. Cockcroft, and M. M. Barrowman. 1985. Stimulated neutrophils from patients with autosomal recessive chronic granulomatous disease fail to phosphorylate a $M_{\mathrm{r}}-44,000$ protein. Nature (Lond.). 316:547-549.

28. Curnutte, J. T., P. J. Scott, and L. A. Mayo. 1989. The cytosolic components of the respiratory burst oxidase: resolution of four components, two of which are missing in complementing types of chronic granulomatous disease. Proc. Natl. Acad. Sci. USA. 86:825-829. 